\title{
Comparative study on consumption pattern of preserved foods
}

\author{
Rajdeep Kaur and Charanjeet Kaur
}

\begin{abstract}
Food, clothing and shelter are the three basic needs of human beings. Most fruits and vegetables are edible only for a very short time, unless they are promptly and properly preserved. To make food palatable and digestible, various preserved foods are added in diet. Looking into this scenario, a study was undertaken to compare the consumption pattern of army families and farm families in regards to preserved foods. All the respondents (100\%) from both army and farm families consumed pickles daily. Consumption pattern of chutney for farm family respondents was more as compared to army family respondents. Regarding the consumption of murabbas, only 10 per cent army family respondents consumed it daily, while none of the farm family respondents consumed murabba.
\end{abstract}

Key Words : Army family, Farm family, Consumption pattern, Preserved food

How to cite this article : Kaur, Rajdeep and Kaur, Charanjeet (2014). Comparative study on consumption pattern of preserved foods. Food Sci. Res. J., 5(2): 110113 . 